\title{
A randomised controlled trial of a theory of planned behaviour to increase fruit and vegetable consumption: Fresh Facts
}

\author{
Emily J. Kothe ${ }^{1 *}$ and Barbara A Mullan ${ }^{2}$ \\ ${ }^{1}$ School of Psychology, Deakin University, Australia \\ ${ }^{1}$ School of Psychology, Curtin University, Australia
}

${ }^{*}$ Requests for reprints should be addressed to Dr. Emily Kothe, School of Psychology, Deakin University VIC 3125, Australia (e-mail: emily.kothe@deakin.edu.au, phone number: +61 3 92445599). 


\begin{abstract}
Young adults are less likely than other adults to consume fruit and vegetables. Fresh Facts is a theory of planned behaviour based intervention designed to promote fruit and vegetable consumption. The present study sought to evaluate Fresh Facts using a randomised controlled trial. Australian young adults $(n=162)$ were allocated to the Fresh Facts intervention or to the control group in 2011. Intervention participants received automated email messages promoting fruit and vegetable consumption every 3 days over the course of the 1 month intervention. Messages targeted attitude, subjective norm, and perceived behavioural control. Theory of planned behaviour variables and fruit and vegetable intake were measured at baseline and post-intervention (Day 30). Significant increases in attitude and subjective norm relative to control were found among Fresh Facts participants. However intention, perceived behavioural control and fruit and vegetable consumption did not change as a result of the intervention. Changes in intention reported by each participant between baseline and followup were not correlated with corresponding changes in fruit and vegetable consumption. Fresh Facts was not successful in increasing fruit and vegetable consumption. Current evidence does not support the use of the theory of planned behaviour in the design of interventions to increase fruit and vegetable intake in this population.
\end{abstract}


Despite the substantial benefits of fruit and vegetable consumption for physical health and reduction of disease risk (Dauchet, Amouyel, \& Dallongeville, 2009; Dauchet, Amouyel, Hercberg, \& Dallongeville, 2006; FAO/WHO, 2003; He, Nowson, \& MacGregor, 2006; World Health Organisation, 2002), many young adults fail to consume adequate quantities. Australian guidelines for the consumption of fruit and vegetables recommend a daily intake of two servings of fruit and five servings of vegetables (National Health and Medical Research Council, 2003). Age-stratified analyses indicate that in Australia, as in many other regions, young adults are less likely than other adults to meet dietary guidelines (Australian Bureau of Statistics, 1997; World Health Organisation, 2004). This pattern of inadequate consumption suggests the need for nutrition interventions designed to specifically target this age group.

One recent intervention that used health behaviour theory to design and evaluate an intervention for this population is Fresh Facts (Kothe \& Mullan, 2012; Kothe, Mullan, \& Butow, 2012). The Fresh Facts intervention is based on the Theory of Planned Behaviour (Ajzen, 1991; Fishbein \& Ajzen, 2010) and was designed to increase fruit and vegetable consumption through email-delivered messages. According to the Theory of Planned Behaviour, intention is the most proximal predictor of behaviour. Intention in turn is predicted by three constructs, attitude (evaluation of the behaviour and its expected outcomes), subjective norm (perceived social pressure to engage in the behaviour), and perceived behavioural control (perceived ease or difficulty of engaging in the behaviour). The Fresh Facts intervention targets these three factors in order to increase fruit and vegetable consumption (Kothe, et al., 2012). Preliminary evaluations of the intervention have indicated that Fresh Facts is highly rated by participants as interesting, credible, logical, easy to understand, useful and personally relevant (Kothe \& Mullan, 2012). It also appears that Fresh 
Facts may lead to clinically significant increases in fruit and vegetable consumption (Kothe, et al., 2012). However, since the previous evaluation of the efficacy of Fresh Facts did not include a control group (Kothe, et al., 2012), it was not possible to determine whether reported changes in fruit and vegetable consumption reflected actual changes in intake as a result of the intervention or were an artefact of the experimental design, or whether such changes were related to natural changes in TPB constructs. These methodological limitations clearly demonstrate the need for a randomised controlled trial of the Fresh Facts intervention in order to properly test and evaluate the effect of the intervention on fruit and vegetable intake and theory of planned behaviour variables. The intervention was developed using an intervention mapping approach to the selection of intervention targets (Bartholomew, Parcel, Kok, \& Gottlieb, 2001). The strategy of attempting to increase fruit and vegetable consumption by seeking to change TPB-related constructs. This intervention approach was selected on the basis of studies showing that the theory consistently predicts fruit and vegetable intake and research that has suggested the use of this theory in the design and evaluation of interventions to improve fruit and vegetable intake (Allom \& Mullan, 2011; Collins \& Mullan, 2011; Guillaumie, Godin, \& Vézina-Im, 2010; Kothe, et al., 2012), and that the web-based interventions based on this theory appear to be more successful that interventions based on other theories or that lack an underlying theoretical approach (Webb, Joseph, Yardley, \& Michie, 2010). The purpose of this research was to empirically investigate the potential for this theory to be applied in the context of fruit and vegetable consumption.

For example, Guillamie et. al. (2010) conducted a review of the use of social cognition models in the prediction of fruit and vegetable consumption in order to guide intervention development. Their results suggested that the TPB was the preferred model for explained 
fruit and vegetable intake intention and behaviour (Guillaumie, et al., 2010). In the context of the young adults, previous research conducted as part of the development of Fresh Facts found that intention accounted for $24.3 \%$ of the variance in fruit and vegetable intake (Kothe, et al., 2012). In turn, TPB variables (attitude, subjective norm, and perceived behavioural control) accounted for $55 \%$ of the variance in intention. Attitude, perceived behavioural control and subjective norm were each significant predictors of behaviour (Kothe, et al., 2012). Together these two strands of evidence provide support for the strategy of increasing fruit and vegetable consumption by targeting attitude, subjective norm, and PBC.

The present study was intended to replicate and extend findings from the previous evaluations of the intervention through the addition of a control group. The aims of the study were to evaluate the impact of the intervention on theory of planned behaviour variables and fruit and vegetable consumption and to investigate the extent to which intervention effects could be explained using the processes of change implied by the theory of planned behaviour. It was hypothesised that exposure to the intervention would result in greater changes in attitude, subjective norm, perceived behavioural control, intention, and fruit and vegetable consumption relative to the control group.

\section{Method}

\section{Participants and Procedure}

First year undergraduate students from an Australian University were recruited to the study. All participants were enrolled in an introductory psychology course and received course credit for their participation. As with previous evaluations of Fresh Facts, all aspects of the study occurred online and could be completed from any computer with internet access (Kothe, et al., 2012). 
After completing a consent form online, participants were computer randomised to the intervention or control group. All participants completed a baseline questionnaire at Time 1, which included measures of demographics; fruit and vegetable intake; and a TPB questionnaire. Intervention participants received the Fresh Facts intervention (described below) via email over the 30 day intervention period. All participants received an invitation to complete the follow-up questionnaire on Day 30. The Time 2 questionnaire included a second administration of the fruit and vegetable consumption measure and TPB items. This study was approved by the University Human Research Ethics Committee.

\section{The Fresh Facts Intervention}

The intervention consisted of a 30-day program designed to target attitude, subjective norm, and perceived behavioural control. Participants in the intervention condition received automated intervention messages every 3 days. As described elsewhere (Kothe, et al., 2012), the design of intervention content for the Fresh Facts intervention was guided by the taxonomy of behaviour-change techniques and interviews with members of the target population (Abraham \& Michie, 2008). All techniques used in the present study have previously been identified as potentially being linked to attitude, subjective norm, and/or PBC (Abraham, Kok, Schaalma, \& Luszczynska, 2010). For a summary of the intervention techniques used in the present study see Table 1. Example intervention messages are available in the supplementary material (Appendix A).

\section{[Table 1 about here]}

\section{Measures}

Theory of planned behaviour constructs (intention, attitude, subjective norm and perceived behavioural control) were assessed using a purpose designed questionnaire. The 
questionnaire has been described in detail elsewhere (Kothe, et al., 2012). Intention, attitude, subjective norm and PBC were all assessed using a 100 point visual analogue scale at both baseline and post-intervention follow-up. Fruit and vegetable consumption was measured using a brief self-report measure of previous day consumption (e.g. How many servings of fruit did you eat yesterday?). Scores were summed to create a composite score of the previous day fruit and vegetable consumption.

\section{Statistical analyses}

A series of two-way analyses of variance (ANOVAs) were conducted to ensure that randomisation of participants to conditions was successful and that participants who dropped out of the study between baseline and follow-up $(n=30)$ did not systematically differ from those who completed both time points $(n=132)$ on any of the primary or secondary endpoints.

Intervention effects were formally tested using a series of repeated measures ANOVAs. The dependent variables were the fruit and vegetable consumption and theory of planned behaviour measures. Time of assessment was entered as a within-subjects factor and condition was entered as a between-subjects factor. A time-by-group interaction term was calculated to investigate differences in the rate of change between each group for all of the primary and secondary endpoints. The relationships between primary and secondary endpoints and between changes in each of these constructs were evaluated using bivariate correlations.

Sensitivity analyses were conducted in G*Power to evaluate the sufficiency of the obtained sample size. The study was sufficiently power to detect intervention effects of $\eta^{2} \geq 0.01$ $(\alpha=.05$ and $1-\beta=.08)$. This is typically classified as a small effect (Schneider, Gruman, \& 
Coutts, 2005).

\section{Results}

One hundred and eighty participants completed baseline data collection. Age in years of the sample ranged from 18 to 25 , with a mean age of 18.84 years $(S D=1.30)$. The majority of participants (83.3\%) were female (see Table 2). Across the entire cohort, $82 \%$ of individuals did not consume recommended quantities of fruit and vegetables at baseline (mean $=4.64$ servings/day, range 0-10 servings/day). Consistent with research suggesting beneficial effects of increasing fruit and vegetable consumption beyond the seven servings recommended in Australian guidelines (FAO/WHO, 2003), participants who reported that they were meeting dietary recommendations at baseline were included in the final dataset (see Figure 1 for the flow of participants through the study).

\section{[Table 2 about here]}

\section{Tests of representativeness}

There were no significant differences between the control and intervention group or between completers $(n=132)$ and drop-outs $(n=30)$ on any of the primary or secondary endpoints. Analyses of condition $\mathrm{x}$ attrition interactions indicated an equivalent effect of attrition between the two conditions.

\section{Testing intervention effects}

Means and standard deviations for each variable at each time point are shown in Table 3.

Consistent with the lack of between-group differences reported above, there was no main effect of condition for any of the primary or secondary endpoints. However, there was a main effect for time on several variables of interest. There was a significant main effect for time on subjective norm, $F(1,130)=42.25 p<.001 \mathrm{~d}=0.56$; perceived behavioural control, $F(1,130)$ $=13.059 p<.001 \mathrm{~d}=0.33$; intention $F(1,130)=23.345 p<.001 \mathrm{~d}=0.43$; and fruit and 
vegetable consumption, $F(1,130)=8.45 p=.004 \mathrm{~d}=0.25$. This indicates that across the entire cohort subjective norm, perceived behavioural control, intention, and fruit and vegetable consumption changed significantly between baseline and follow-up. There was no time effect for attitude $(\mathrm{d}=0.07)$.

[Table 3 about here]

Interaction terms revealed intervention effects across a range of endpoints. There was a significant time $\mathrm{x}$ condition interaction for attitude, indicating that change in attitude between baseline and follow-up varied as a function of condition, $F(1,130)=6.137 p=.015 \mathrm{~d}=0.43$. The increase in attitude between baseline and follow-up was significantly greater in the intervention group than in the control group. There was also a significant time $\mathrm{x}$ condition interaction for subjective norm, $F(1,130)=4.919 p=.028 \mathrm{~d}=0.39$, indicating that change in subjective norm between baseline and follow-up was significantly greater in the intervention group than in the control group. The time $\mathrm{x}$ condition interaction was not significant for perceived behavioural control, $F(1,130)=0.001 p=.977 \mathrm{~d}=0.005$; intention, $F(1,130)=$ $0.046 p=.830 \mathrm{~d}=0.04$; or fruit and vegetable consumption, $F(1,130)=0.459 p=.499 \mathrm{~d}=$ 0.12 .

Table 4 presents the relationships between theory of planned behaviour variables at each time point and changes in these variables across the course of the intervention. Consistent with the theory of planned behaviour, intention was correlated with fruit and vegetable consumption at each time point. Similarly, attitude, subjective norm, and perceived behavioural control were associated with intention at both time 1 and time 2 . However, change in fruit and vegetable consumption between time 1 and time 2 was not associated with change in intention, nor was change in intention associated with change in attitude or perceived behavioural control. Change in intention was significantly associated with change in subjective norm. 
[Table 4 about here]

\section{Discussion}

Initial evaluation of the impact of this theory of planned behaviour based intervention on fruit and vegetable consumption was promising, with results showing that participants who were exposed to the Fresh Facts intervention reported an increase in fruit and vegetable consumption between baseline and follow-up (Kothe, et al., 2012). However, the inclusion of a control group in the present study shows that although fruit and vegetable consumption, subjective norm, and intention all changed between baseline and follow-up, the Fresh Facts intervention was not the sole cause of these changes. Instead, the only significant intervention effects were increases in attitude and subjective norm in the intervention group relative to control. There are two major interpretations for the lack of intervention effects shown in this study. The first is that the intervention was ineffective at changing key constructs and as such could not lead to change in fruit and vegetable consumption; the second is that changes in theory of planned behaviour constructs do not lead to behaviour change (i.e. change in intention is not associated with change in behaviour).

The first interpretation is not consistent with the observed pattern of results. The hypothesised mechanisms of action for the Fresh Facts intervention was that change in attitude, perceived behavioural control, subjective norm, or any combination thereof would lead to change in intention, which in turn would lead to an increase in fruit and vegetable consumption in the intervention group (Fishbein \& Ajzen, 2010; Kothe, et al., 2012). As the time x condition interactions show, the intervention was successful in achieving change in two of the three intervention targets: attitude and subjective norm. According to the theoretical framework utilised in this intervention, these changes were expected to have flow-on effects through 
change in intention leading to change in behaviour (Fishbein \& Ajzen, 2010).

However, as with the previous Fresh Fact study (Kothe, et al., 2012), changes in attitude and perceived behavioural control were not related to change in intention and change in intention was not correlated with change in behaviour. This suggests that significant changes in attitude and subjective norm did not have flow-on effects to change in intention. As such, the assumption that sufficiently large changes in these constructs would be translated to change in fruit and vegetable consumption is not supported by this data. Given the similarity between the pattern of results observed in this study and some recent studies that have also failed to demonstrate mediation of behaviour change through theory of planned behaviour constructs (Hardeman, Kinmonth, Michie, \& Sutton, 2011; Kellar \& Abraham, 2005) and with research that has sought to apply the TPB to the prediction of naturalistic change in behaviour (Armitage, Reid, \& Spencer, 2011), researchers need to exercise some caution in assuming that the theory of planned behaviour can provide a complete model of behaviour change. In particular, current literature does not provide consistent evidence of an association between change in intention and change in behaviour. As such, researchers investigating behaviour change processes may wish to consider whether behaviour change could be more effectively brought about by using theories which include post-intentional predictors of behaviour such as the health action process approach (Schwarzer, 1992) and temporal self-regulation theory (Hall \& Fong, 2007) or through the addition use of behaviour change techniques such as goal setting or implementation intentions (Gollwitzer, 1999; Sheeran, Milne, Webb, \& Gollwitzer, 2005) within intervention design. Such models provide explanations for behaviour change that do not rely on an association between change in intention and change in behaviour (e.g. change in behaviour being associated with change in habit strength). However, as this research shows, well designed experimental studies are needed to examine whether changes 
in such constructs do reliably explain change in behaviour.

Across the entire cohort, there were significant increases in subjective norm, perceived behavioural control, intention and fruit and vegetable consumption over the study period. These changes were equally likely to occur in participants in the control condition as in the intervention groups, meaning that the changes do not reflect the impact of the intervention on these factors but are more likely some artefact of the study design. Given the similarity in the cohort effects across this study and previous evaluations of Fresh Facts (Kothe, et al., 2012), it is reasonable to assume increases in these variables were driven by the same factors across the two studies. One possible interpretation for changes in the fruit and vegetable consumption, which occurred across the entire cohort, is the effect of the measurement of fruit and vegetable consumption and its determinants. It has been repeatedly demonstrated that the use of questionnaires designed to measure theory-of-planned-behaviour variables, particularly intention, can increase the performance of behaviour (Armitage, 2009; Falk, 2010; Sherman, 1980). This effect is known as the 'mere-measurement effect' (Chapman, 2001), the 'question-behaviour' effect (Sprott et al., 2006), or 'the self-erasing error of prediction' (Sherman, 1980). This effect has been demonstrated in a range of behaviours across different behavioural domains (e.g., Chandon, Morwitz, \& Reinartz, 2005; Sherman, 1980; Sprott, et al., 2006) and has been shown to persist regardless of whether self-report or objective measures of behaviour are used (e.g., Armitage, 2009). It has been suggested that the effect may occur because the measurement of intention may increase the salience of beliefs relating to the target behaviour and that this increase in salience may actually act as an intervention (Falk, 2010; Morwitz \& Fitzsimons, 2004). In this study, such an effect could explain increases in theory of planned behaviour variables and behaviour between Time 1 and Time 2. 
A second interpretation of this pattern of results relates to the nature of participants recruited to the present study. High motivation of participants at baseline has been presented as a possible explanation of cohort-wide change in previous intervention studies (e.g., Kinmonth et al., 2008), and is a limitation of randomised controlled trials across most health domains. In the present study, intention to consume fruit and vegetables was high at baseline. This high level of motivation could indicate that individuals in the study cohort may have had preexisting motivation to change their behaviour. Indeed, participants who volunteered to participate in the trial did so knowing that the study was investigating fruit and vegetable consumption; this may have led already strongly motivated participants to increase their consumption regardless of exposure to intervention materials. This effect may have acted either independently or in combination with possible measurement effects to lead to increases in fruit and vegetable consumption and related cognitions across the course of the study.

Given the design of the present study, it is not possible to determine the influence of either of these possible drivers of cohort wide change. In order to distinguish between these two interpretations, future researchers may wish to investigate the effects of Fresh Facts, or a similar intervention, using a Solomon four-group design (Solomon, 1949) and a study that purposefully recruits individuals who are less motivated to change at baseline. Although it should be noted that recruitment in such studies may be difficult to achieve.

\section{Study limitations and strengths}

The present study has several methodological strengths and limitations that must be considered in the interpretation of findings. This study relied on self-reported measures of fruit and vegetable intake when assessing change in fruit and vegetable consumption. This 
limitation, common to most studies of eating behaviour, may have led to the over- or underestimation of fruit and vegetable consumption. Further, the measure used in the current study assessed fruit and vegetable consumption on the basis of previous day consumption at two time points, baseline and follow-up. This measure is similar to the measure of fruit and vegetable consumption used in the National Health Survey and in evaluations of the success of the Go for $2 \& 5$ health-promotion campaign (Australian Bureau of Statistics, 2009; Woolcott Research, 2007). Although the use of a 24 hour dietary recall is the gold standard for assessment of fruit and vegetable consumption such a measure was not feasible in this study. Short dietary instruments of this type have been shown to be well correlated with estimates of fruit and vegetable consumption obtained from 24 hour dietary recall (Peterson et al., 2008). This should be taken into account when interpreting results. Further, the use of a student sample in the present study should also be considered when interpreting results. However, given evidence that the use of such samples is likely to overestimate the applicability of the theory (McEachan, Conner, Taylor, \& Lawton, 2011), this criticism may be less relevant in light of the null results.

The timing of data collection should also be borne in mind when evaluating the extent to which the theory of planned behaviour can be used as a model of behaviour change. While the use of baseline and post-intervention time points to evaluate theory based interventions is relatively standard, these time points may not be ideal for evaluating the relationships between changes in different constructs. It may be the case that changes in theory of planned behaviour cognitions need a longer period of time to translate to changes in intention and behaviour than was investigated in the current study. Empirical work in needed to investigate how changes in these cognitions (whether occurring naturally or as a result of intervention programs) progress to changes in other constructs over time. Novel methodological 
approaches, such as the use of experience sampling methodology (Bolger, Davis, \& Rafaeli, 2003), have been useful in investigating these issues in other contexts (Fuller-Tyszkiewicz, Skouteris, \& Mccabe, 2013) and may be a valuable addition to the investigation of behaviour change using models such as the theory of planned behaviour.

Another important factor to consider when evaluating the effect of any intervention is that of intervention fidelity and adherence. In particular, the level of engagement that participants had with the Fresh Facts intervention may have influenced the potential for the intervention to lead to changes in fruit and vegetable consumption. While the current study did not measure intervention adherence, a previous study which investigated the feasibility and acceptability of an earlier version of the Fresh Facts intervention found that most participants did report engaging with the intervention (Kothe \& Mullan, 2012). While the possibility that null effects in this trial were the result of poor intervention adherence cannot be entirely accounted for; the previous research would indicate that this is unlikely to be the sole determinant of the intervention's lack of efficacy.

The Fresh Facts study was only the second intervention to evaluate the utility of the theory of planned behaviour in the design and evaluation of interventions to increase fruit and vegetable consumption. Despite using a more responsive measure of fruit and vegetable consumption and higher intensity intervention materials, the Fresh Facts intervention mirrored previous results by failing to bring about significant changes in fruit and vegetable consumption (Kellar \& Abraham, 2005). Taken together these studies would suggest that the theory of planned behaviour may not be suitable for use in the design of interventions to improve fruit and vegetable consumption. 
One of the primary strengths of the present work was the evaluation of the theory of planned behaviour in the context of behaviour change. As have been noted by other prominent researchers within health psychology, experimental tests of the TPB are relatively rare (Hardeman et al., 2002; Sniehotta, Presseau, \& Araújo-Soares, 2013). Evaluation of models of behaviour, such as the theory of planned behaviour, through intervention research is an important step forward in evaluating the evidence to support the use of these theories (Michie \& Johnston, 2012; Noar \& Head, 2013). This research adds to the small body of work that has previously tested pathways of behaviour change, both in fruit and vegetable consumption and in the theory of planned behaviour literature (e.g., Elliott \& Armitage, 2009; Hardeman, et al., 2011). The results add to the body growing body of research suggesting that the theory may not adequately account for behaviour change (e.g., Hardeman, et al., 2011). This finding is one that could be evaluated in more detail in future research because it is important to discover how behaviour change might be more adequately explained.

From a practical perspective, this study clearly shows the advantages of measuring theoryrelevant variables when assessing theory-based behaviour change interventions, because the measurement of these variables provides vital information behind the reasons why the intervention may have failed to bring about change in fruit and vegetable consumption. The results clearly show difficulty in achieving change in attitude, subjective norm, and perceived behavioural control of significant magnitude to achieve change in intention. They also challenge the assumption that change in intention is likely to lead to change in behaviour in the present context. This is incredibly valuable information in the evaluation of an intervention like Fresh Facts because it allows the failure of the intervention to be clearly interpreted in light of the problematic theoretical assumptions rather than in light of the intensity or modality of intervention materials. In the absence of detailed information about 
theoretical constructs, the failure of the intervention might be interpreted as a failure to achieve change in intervention targets (i.e., subjective norm, attitude, perceived behavioural control, or all of these) or of the behaviour change techniques used in the intervention. Conversely, had the intervention failed to bring about changes in intervention targets, the collection of information about the impact of the intervention on those targets would have allowed for interpretation of those results as indicating problems with the intervention specifically rather than with the theoretical model on which it was based. It is always difficult to determine whether the failure of a theory-based intervention to achieve desired changes in behaviour are indicative of problems with the individual intervention or with the theory itself. However, the experimental tests of theory-based interventions are vital to establishing a body of evidence that can ultimately used to answer this question. If interventions based on a given theory consistently fail to achieve changes in behaviour - then that would indicate broader issues with the theory that are unlikely to attributable to potential flaws in individual interventions.

\section{Implications for Future Work}

Both Fresh Facts studies have found significant differences in fruit and vegetable consumption, intention, subjective norm, and perceived behavioural control between baseline and follow-up. These changes were equally likely to occur in participants in the control condition as in the intervention groups, meaning that the changes do not reflect the impact of the intervention on these factors but rather are more likely some artefact of the study design. Investigation of possible interpretations for such change would be a valuable line of inquiry in further studies.

Ultimately, the intervention tested here does appear to be effective in changing target 
cognitions. However, changes in these cognitions do not appear to be effectively translated to change in fruit and vegetable consumption. Further research should be conducted to determine whether change in attitude and subjective norm can be effectively translated to change in fruit and vegetable consumption, for example through the use of higher intensity intervention modalities. However, given the relatively positive attitudes and subjective norms held by most individuals towards fruit and vegetable consumption, such studies may need to apply the model to less desirable behaviours in order to avoid ceiling effects. Given gender differences in the determinants of fruit and vegetable consumption identified in previous research (Baker \& Wardle, 2003; Emanuel, McCully, Gallagher, \& Updegraff, 2012), future work might also consider whether interventions tailored to participant gender may result in larger intervention effects.

The selection of behaviour change techniques using the taxonomy of behaviour change techniques reported by Abraham et. al (2010) and the subsequent reporting of the techniques using this taxonomy was a key component of the Fresh Facts intervention design and evaluation process. However, progress in developing taxonomies are still ongoing (Michie et al., 2013), research seeking to identify those techniques that are most effective in changing behaviour in its infancy (Michie, Abraham, Whittington, McAteer, \& Gupta, 2009; Michie \& Johnston, 2012; Webb, et al., 2010), and formal attempts to link behaviour change techniques to theoretical constructs are extremely limited. As such, there may be techniques that were not included in the Fresh Facts intervention but that might also be appropriate when seeking to change attitude, subjective norm, and perceived behavioural control. For example, a wealth of research on cognitive dissonance has suggested that this attitude change related technique (or group of techniques) can be successful in changing health behaviours (Freijy \& Kothe, 2013). Similarly, although the current intervention sought to change perceived behavioural 
control primarily through arguments to bolster self-efficacy and by providing instruction, a range of other potential methods for increasing PBC have been identified as relevant by past TPB researchers (Hardeman, et al., 2002). Research identifying behaviour change techniques that are most likely to achieve changes in targeted constructs is a valuable avenue of research. However, given that the Fresh Facts was already successful changing both subjective norm and attitude the use of other techniques to change attitude, subjective norm, and perceived behavioural control may have had limited effects on the overall outcome of this intervention.

A major justification for the selection of the theory of planned behaviour for use in the current study was the need to address assumptions about the utility of the theory, both within the area of fruit and vegetable consumption and within the context of behaviour change more broadly. As such, the inclusion of non-theory-based variables, and behaviour change techniques that target such variables, to the design and evaluation of the intervention would have significantly weakened the ability to address these research questions. However, given that the intervention based on the theory of planned behaviour did not result in significant increases in fruit and vegetable consumption, future researchers should consider the inclusion of behaviour change techniques targeting other determinants of behaviour in order to bring about increases in fruit and vegetable consumption.

\section{Conclusion}

When proposing that the theory of planned behaviour be used in interventions designed to bring about behaviour change, it is assumed that change in the predictors of behaviour (i.e., intention, subjective norm, attitude, and perceived behavioural control) is likely to lead to change in fruit and vegetable consumption (Armitage, et al., 2011; Elliott, Thomson, Robertson, Stephenson, \& Wicks; Fishbein \& Ajzen, 2010). However, the research presented 
here suggests that this may not be the case. Instead, there appears to be a very low correlation between change in intention and change in behaviour. This has implications for the use of the theory of planned behaviour in explaining behaviour change generally. On the basis of these findings, it would appear that researchers should be cautious in interpreting a model's strong predictive power as evidence that the model will provide a good model of behaviour change. Well-designed experimental studies are needed to further explore the causal relationship between change in intention and behaviour change; both in the context of fruit and vegetable consumption and for health behaviours more broadly. However, on the basis of the current body of research, the use of the theory of planned behaviour for the promotion of fruit and vegetable consumption does not appear to be empirically supported. 


\section{References}

Abraham, C., Kok, G., Schaalma, H., \& Luszczynska, A. (2010). Health Promotion. In P.R. Martin, F. Cheung, M. Kyrios, L. Littlefield, L. Knowles, M. Overmier \& M. P. J. (Eds.), The International Association of Applied Psychology Handbook of Applied Psychology. Oxford: Wiley-Blackwell.

Abraham, C., \& Michie, S. (2008). A taxonomy of behavior change techniques used in interventions. Health Psychology, 27(3), 379-387.

Ajzen, I. (1991). The theory of planned behavior. Organizational Behavior and Human Decision Processes, 50(2), 179-211.

Allom, V., \& Mullan, B. (2011). Self-regulation versus habit: The influence of self-schema on fruit and vegetable consumption. Psychology \& Health, 27(Supplement 2).

Armitage, C. J. (2009). Is there utility in the transtheoretical model? British journal of health psychology, 14(2), 195-210.

Armitage, C. J., Reid, J. C., \& Spencer, C. P. (2011). Changes in cognition and behaviour: a causal analysis of single-occupancy car use in a rural community. Transportmetrica, $1-10$.

Australian Bureau of Statistics. (1997). National Nutrition Survey: Selected Highlights, Australia, 1995 Canberra.

Australian Bureau of Statistics. (2009). National Health Survey. Canberra: Australian Bureau of Statistics.

Baker, A. H., \& Wardle, J. (2003). Sex differences in fruit and vegetable intake in older adults. Appetite, 40(3), 269-275.

Bartholomew, L. K., Parcel, G. S., Kok, G., \& Gottlieb, N. H. (2001). Intervention Mapping: Designing theory and evidence-based health promotion programs. Mayfield, Mountain View, $C A$. 
Bolger, N., Davis, A., \& Rafaeli, E. (2003). Diary methods: Capturing life as it is lived. Annual Review of Psychology, 54(1), 579-616.

Chapman, K. J. (2001). Measuring intent: There's nothing mere" about mere measurement effects. Psychology and Marketing, 18(8).

Collins, A., \& Mullan, B. (2011). An extension of the theory of planned behavior to predict immediate hedonic behaviors and distal benefit behaviors. Food Quality and Preference, 22(7).

Dauchet, L., Amouyel, P., \& Dallongeville, J. (2009). Fruits, vegetables and coronary heart disease. Nature Reviews Cardiology, 6(9), 599-608.

Dauchet, L., Amouyel, P., Hercberg, S., \& Dallongeville, J. (2006). Fruit and Vegetable Consumption and Risk of Coronary Heart Disease: A Meta-Analysis of Cohort Studies. Journal of Nutrition, 136(10), 2588-2593.

Elliott, M. A., \& Armitage, C. J. (2009). Promoting drivers' compliance with speed limits: Testing an intervention based on the theory of planned behaviour. British Journal of Psychology, 100(1), 111-132.

Elliott, M. A., Thomson, J. A., Robertson, K., Stephenson, C., \& Wicks, J. Evidence that changes in social cognitions predict changes in self-reported driver behavior: Causal analyses of two-wave panel data. Accident Analysis \&amp; Prevention(0).

Emanuel, A. S., McCully, S. N., Gallagher, K. M., \& Updegraff, J. A. (2012). Theory of Planned Behavior explains gender difference in fruit and vegetable consumption. Appetite.

FAO/WHO. (2003). Diet, nutrition and the prevention of chronic diseases. Report of a Joint FAO/WHO Expert Consultation Geneva: World Health Organization

Fishbein, M., \& Ajzen, I. (2010). Predicting and changing behavior: The reasoned action approach. New York: Psychology Press. 
Freijy, T., \& Kothe, E. J. (2013). Dissonance-based interventions for health behaviour change: A systematic review. British journal of health psychology, 18(2), 310-337.

Fuller-Tyszkiewicz, M., Skouteris, H., \& Mccabe, M. (2013). A re-examination of the benefits of exercise for state body satisfaction: Consideration of individual difference factors. Journal of Sports Sciences(ahead-of-print), 1-8.

Gollwitzer, P. M. (1999). Implementation intentions: Strong effects of simple plans. American Psychologist, 54(7), 493-503.

Guillaumie, L., Godin, G., \& Vézina-Im, L. A. (2010). Psychosocial determinants of fruit and vegetable intake in adult population: a systematic review. International Journal of Behavioral Nutrition and Physical Activity, 7(1), 12.

Hall, P. A., \& Fong, G. T. (2007). Temporal self-regulation theory: A model for individual health behavior. Health Psychology Review, 1(1), 6-52.

Hardeman, W., Johnston, M., Johnston, D., Bonetti, D., Wareham, N., \& Kinmonth, A. (2002). Application of the theory of planned behaviour in behaviour change interventions: a systematic review. Psychology \& Health, 17(2), 123-158.

Hardeman, W., Kinmonth, A. L., Michie, S., \& Sutton, S. (2011). Theory of planned behaviour cognitions do not predict self reported or objective physical activity levels or change in the ProActive trial. British journal of health psychology, 16(1), 135-150.

He, F. J., Nowson, C. A., \& MacGregor, G. A. (2006). Fruit and vegetable consumption and stroke: meta-analysis of cohort studies. Lancet, 367(9507), 320-326.

Kellar, I., \& Abraham, C. (2005). Randomized controlled trial of a brief research-based intervention promoting fruit and vegetable consumption. British Journal of Health Psychology, 10(4), 543-558.

Kothe, E. J., \& Mullan, B. A. (2012). Acceptability of a theory of planned behaviour emailbased nutrition intervention. Health Promotion International. 
Kothe, E. J., Mullan, B. A., \& Butow, P. (2012). Promoting fruit and vegetable consumption: testing an intervention based on the theory of planned behaviour. Appetite, 58(3).

McEachan, R. R. C., Conner, M., Taylor, N. J., \& Lawton, R. J. (2011). Prospective prediction of health-related behaviours with the Theory of Planned Behaviour: a meta-analysis. Health Psychology Review, 5(2), 97-144.

Michie, S., Abraham, C., Whittington, C., McAteer, J., \& Gupta, S. (2009). Effective techniques in healthy eating and physical activity interventions: a meta-regression. Health Psychology, 28(6), 690.

Michie, S., \& Johnston, M. (2012). Theories and techniques of behaviour change: Developing a cumulative science of behaviour change. Health Psychology Review, 6(1), 1-6.

Michie, S., Richardson, M., Johnston, M., Abraham, C., Francis, J., Hardeman, W., et al. (2013). The Behavior Change Technique Taxonomy (v1) of 93 Hierarchically Clustered Techniques: Building an International Consensus for the Reporting of Behavior Change Interventions. Annals of Behavioral Medicine, 46(1), 81-95.

National Health and Medical Research Council. (2003). Dietary Guidelines for Australian Adults. Canberra: Commonwealth of Australia

Noar, S. M., \& Head, K. J. (2013). Mind the gap: bringing our theories in line with the empirical data - a response to commentaries. Health Psychology Review, 1-5.

Peterson, K. E., Hebert, J. R., Hurley, T. G., Resnicow, K., Thompson, F. E., Greene, G. W., et al. (2008). Accuracy and precision of two short screeners to assess change in fruit and vegetable consumption among diverse populations participating in health promotion intervention trials. The Journal of nutrition, 138(1), 218S-225S.

Schneider, F. W., Gruman, J. A., \& Coutts, L. M. (2005). Applied social psychology: Understanding and addressing social and practical problems: Sage Publications, Inc. 
Schwarzer, R. (1992). Self-efficacy in the adoption and maintenance of health behaviors: Theoretical approaches and a new model.

Sheeran, P., Milne, S., Webb, T. L., \& Gollwitzer, P. M. (2005). Implementation intentions and health behaviour. In M. Conner \& P. Norman (Eds.), Predicting health behaviour. Research and practice with social cognition models (pp. 276-323). Berkshire, UK: : Open University Press. .

Sniehotta, F., Presseau, J., \& Araújo-Soares, V. (2013). Time to Retire the Theory of Planned Behaviour. Health Psychology Review, 1-8.

Webb, T. L., Joseph, J., Yardley, L., \& Michie, S. (2010). Using the internet to promote health behavior change: a systematic review and meta-analysis of the impact of theoretical basis, use of behavior change techniques, and mode of delivery on efficacy. Journal of Medical Internet Research, 12(1).

Woolcott Research. (2007). Evaluation of the National Go for $2 \& 5$ Campaign: Prepared for Australian Government Department of Health and Ageing by Woolcott Research Pty Ltd.

World Health Organisation. (2002). The World Health Report: Reducing risks, promoting health. . Geneva: World Health Organization

World Health Organisation. (2004). Comparative quantification of health risks: Global and regional burden of disease attributable to selected major risk factors. Geneva: World Health Organisation, 
Table 1. Summary of behaviour change techniques used in Fresh Facts

\begin{tabular}{|c|c|c|c|c|}
\hline $\begin{array}{l}\text { TPB } \\
\text { variable } \\
\text { targeted }\end{array}$ & $\begin{array}{l}\text { Behaviour } \\
\text { change } \\
\text { technique }\end{array}$ & Definition & $\begin{array}{l}\text { Example of how this } \\
\text { was applied within } \\
\text { Fresh Facts }\end{array}$ & $\begin{array}{l}\text { Example intervention text } \\
\text { using this technique }\end{array}$ \\
\hline \multicolumn{5}{|l|}{ Attitude } \\
\hline & $\begin{array}{l}\text { Provide general } \\
\text { information on } \\
\text { behaviour- } \\
\text { health link }\end{array}$ & $\begin{array}{l}\text { Information about the } \\
\text { relationship between } \\
\text { the behaviour and } \\
\text { health }\end{array}$ & $\begin{array}{l}\text { Factual information } \\
\text { about the link between } \\
\text { fruit and vegetable } \\
\text { consumption and } \\
\text { health outcomes was } \\
\text { provided. }\end{array}$ & $\begin{array}{l}\text { "Did you know that } 9 \% \text { of } \\
\text { cancer in Australia is } \\
\text { caused by not eating } \\
\text { enough fruit and veg?" }\end{array}$ \\
\hline & $\begin{array}{l}\text { Provide general } \\
\text { information on } \\
\text { the material } \\
\text { consequences } \\
\text { of behaviour }\end{array}$ & $\begin{array}{l}\text { Information focusing } \\
\text { on what will happen if } \\
\text { the person performs } \\
\text { the behaviour } \\
\text { including the benefits } \\
\text { and costs (or negative } \\
\text { consequences) of } \\
\text { action or inaction, } \\
\text { including perceived } \\
\text { severity of symptoms }\end{array}$ & $\begin{array}{l}\text { This information was } \\
\text { provided from a } \\
\text { number of different } \\
\text { sources over the course } \\
\text { of the intervention. } \\
\text { Including "experts" } \\
\text { and same age peers } \\
\text { who provided } \\
\text { information about their } \\
\text { own subjective } \\
\text { experience of the link } \\
\text { between their fruit and } \\
\text { vegetable consumption } \\
\text { and health. }\end{array}$ & $\begin{array}{l}\text { "Eating at least two } \\
\text { servings of fruit and five } \\
\text { servings of vegetables each } \\
\text { day reduces your risk of } \\
\text { cancer as well as slashing } \\
\text { your risk of cancer, stroke, } \\
\text { heart disease, and obesity." } \\
\text { "When you eat junk food } \\
\text { you will feel moody, tired } \\
\text { and lazy. But if you eat } \\
\text { fruit and vegetables you get } \\
\text { doses of vitamins that make } \\
\text { you feel good"." }\end{array}$ \\
\hline \multicolumn{5}{|c|}{ Subjective norm } \\
\hline & $\begin{array}{l}\text { Provide } \\
\text { information } \\
\text { about others' } \\
\text { behaviour }\end{array}$ & $\begin{array}{l}\text { Information about } \\
\text { what other are doing, } \\
\text { i.e. indicates that a } \\
\text { particular action or } \\
\text { sequence of actions is } \\
\text { common or } \\
\text { uncommon amongst a } \\
\text { group }\end{array}$ & $\begin{array}{l}\text { Participants were } \\
\text { provided information } \\
\text { about the fruit and } \\
\text { vegetable consumption } \\
\text { of same age peers. }\end{array}$ & $\begin{array}{l}\text { "Most people don't talk } \\
\text { about fruit and vegetables } \\
\text { with their friends - so they } \\
\text { often underestimate the } \\
\text { number of people who do } \\
\text { consume the recommended } \\
\text { quantities of fruit and } \\
\text { vegetables. We surveyed } \\
\text { healthy young adults - } \\
\text { people just like you - as } \\
\text { part of Fresh Fact's } \\
\text { development. More than } \\
65 \% \text { of healthy young } \\
\text { adults eat fruit and } \\
\text { vegetables every day." }\end{array}$ \\
\hline & $\begin{array}{l}\text { Provide } \\
\text { information } \\
\text { about others' } \\
\text { approval }\end{array}$ & $\begin{array}{l}\text { Information about } \\
\text { how other } \\
\text { people/specific others } \\
\text { judge/approve of the } \\
\text { participant's } \\
\text { behaviour }\end{array}$ & $\begin{array}{l}\text { Stories from other } \\
\text { young people were } \\
\text { included to provide } \\
\text { normative messages } \\
\text { about others' approval } \\
\text { (TopPicks). These } \\
\text { messages included } \\
\text { statements designed to } \\
\text { target injunctive norms }\end{array}$ & $\begin{array}{l}\text { "I eat at least } 2 \text { fruit and } 5 \\
\text { veg every day - and I think } \\
\text { everyone should as well" }\end{array}$ \\
\hline
\end{tabular}


Provide opportunities for social comparison
Provide a setting in which social comparison can occur
Individuals were prompted to compare their own fruit and vegetable consumption to other people they knew and to seek advice and support from individuals who were consuming high quantities of fruit and vegetables

"Think about how your friends and family include fruit and vegetables in their lives. How do you measure up?"

"If there are people in your life who are especially good at eating well, why not ask them how they do it?

Talking to others can give you ideas about how to improve your own habits."

\begin{tabular}{|c|c|c|c|c|}
\hline PBC & & & & \\
\hline & $\begin{array}{l}\text { Arguments to } \\
\text { bolster self- } \\
\text { efficacy }\end{array}$ & $\begin{array}{l}\text { Involves telling the } \\
\text { person that they can } \\
\text { successfully perform } \\
\text { the behaviour, arguing } \\
\text { against self-doubts } \\
\text { and asserting that they } \\
\text { can and will succeed }\end{array}$ & $\begin{array}{l}\text { Fresh Facts content } \\
\text { consistently } \\
\text { emphasised that } \\
\text { consumption of fruit } \\
\text { and vegetables was } \\
\text { easy to perform and } \\
\text { achievable for the } \\
\text { individual }\end{array}$ & $\begin{array}{l}\text { "...If they can do it, you } \\
\text { can too!" } \\
\text { "[suggested technique] } \\
\text { makes it easy" }\end{array}$ \\
\hline & $\begin{array}{l}\text { Provide } \\
\text { instruction }\end{array}$ & $\begin{array}{l}\text { Telling participants } \\
\text { how to perform a } \\
\text { behaviour or } \\
\text { preparatory } \\
\text { behaviours, e.g. } \\
\text { instructions providing } \\
\text { "tips" }\end{array}$ & $\begin{array}{l}\text { Young adults who took } \\
\text { part in the early stages } \\
\text { of fruit and vegetables } \\
\text { reported that storage of } \\
\text { fresh fruit and } \\
\text { vegetables was a major } \\
\text { barrier to the regular } \\
\text { consumption of } \\
\text { adequate quantities of } \\
\text { fruit and vegetables. } \\
\text { Participants were } \\
\text { provided with } \\
\text { instruction and "tips" } \\
\text { designed to increase } \\
\text { perception of control } \\
\text { by encouraging } \\
\text { consumption of fruit } \\
\text { and vegetables that did } \\
\text { not present this threat }\end{array}$ & $\begin{array}{l}\text { "Fresh fruit and vegetables } \\
\text { taste great - but they are } \\
\text { not the only option. One } \\
\text { easy way to increase the } \\
\text { amount of fruit and } \\
\text { vegetables you eat without } \\
\text { having to go to the shops all } \\
\text { the time is to eat tinned, } \\
\text { frozen, or dried fruits and } \\
\text { vegetables... This makes it } \\
\text { even easier to eat well."). } \\
\text { "For me the best way to eat } \\
\text { well is to plan ahead. I } \\
\text { order my food online and } \\
\text { always order a variety of } \\
\text { fresh, frozen and tinned } \\
\text { produce ... Having variety } \\
\text { makes it easy". }\end{array}$ \\
\hline
\end{tabular}

*Note examples are not exhaustive, each technique was applied in a number of different ways over the course of the intervention. 
Table 2. Demographic Characteristics of the Baseline Sample recruited from the University of Sydney in 2011

\begin{tabular}{|c|c|c|}
\hline Demographic Characteristic & $\mathrm{N}$ & $\%$ \\
\hline \multicolumn{3}{|l|}{ Gender } \\
\hline Female & 135 & 83.3 \\
\hline Male & 27 & 16.7 \\
\hline \multicolumn{3}{|l|}{ Living Situation } \\
\hline With parents & 127 & 78.4 \\
\hline With friends & 14 & 8.6 \\
\hline Residential college & 6 & 3.7 \\
\hline Alone & 7 & 4.3 \\
\hline With partner & 1 & 0.6 \\
\hline \multicolumn{3}{|l|}{ Ethnicity } \\
\hline Australian & 76 & 46.9 \\
\hline Northeast Asian & 41 & 25.3 \\
\hline Southeast Asian & 12 & 7.4 \\
\hline Southern and Eastern European & 5 & 3.1 \\
\hline Southern and Central Asian & 7 & 4.3 \\
\hline Northwest European & 7 & 4.3 \\
\hline North African and Middle Eastern & 7 & 4.3 \\
\hline New Zealander or Pacific Islander & 2 & 1.2 \\
\hline
\end{tabular}


Table 3 Means (Standard Deviations) for Theory of Planned Behaviour Variables and

Behaviour at Time 1 and Time 2 by Condition among participants recruited from the

University of Sydney in 2011

\begin{tabular}{|c|c|c|c|c|}
\hline & \multicolumn{2}{|l|}{ Baseline } & \multicolumn{2}{|c|}{ Follow-up } \\
\hline & Control & Intervention & Control & Intervention \\
\hline \multirow[t]{2}{*}{ Fruit and vegetable servings/day } & 4.59 & 4.69 & 5.02 & 5.31 \\
\hline & $(2.22)$ & $(1.92)$ & $(2.10)$ & $(2.08)$ \\
\hline \multirow[t]{2}{*}{ Intention } & 67.36 & 70.29 & 74.43 & 77.91 \\
\hline & $(22.89)$ & $(17.25)$ & $(20.48)$ & $(13.96)$ \\
\hline \multirow[t]{2}{*}{ Perceived behavioural control } & 81.43 & 81.98 & 84.51 & 84.67 \\
\hline & $(15.7)$ & $(14.8)$ & $(12.74)$ & $(12.08)$ \\
\hline \multirow[t]{2}{*}{ Attitude } & 91.38 & 89.66 & 90.72 & 91.17 \\
\hline & $(10.48)$ & $(10.39)$ & $(10.32)$ & $(9.72)$ \\
\hline \multirow[t]{2}{*}{ Subjective norm } & 68.18 & 66.63 & 73.77 & 76.23 \\
\hline & $(14.77)$ & $(15.85)$ & $(15.37)$ & $(12.26)$ \\
\hline
\end{tabular}

Note: scores on intention, perceived behavioural control, attitude and subjective norm scales range from 1-100. 
Table 4. Bivariate correlations between theory of planned behaviour variables at each time point and between change in theory of planned behaviour variables for entire cohort recruited from the University of Sydney in 2011

\begin{tabular}{|c|c|c|c|c|c|c|c|c|c|c|c|c|c|c|c|}
\hline & 1 & 2 & 3 & 4 & 5 & 6 & 7 & 8 & 9 & 10 & 11 & 12 & 13 & 14 & 15 \\
\hline 1. Time 1 attitude & - & $.32 * *$ & 0.20 & $.31 * *$ & $.26^{*}$ & $.66 * *$ & $.32 * *$ & $.30 *$ & $.41 * *$ & 0.19 & $-.44 * *$ & 0.04 & 0.05 & 0.00 & -0.08 \\
\hline $\begin{array}{l}\text { 2. Time } 1 \text { subjective } \\
\text { norm }\end{array}$ & $.26^{*}$ & - & $.35 * *$ & $.59 * *$ & $.36 * *$ & 0.23 & $.64 * *$ & $.34 * *$ & $.54 * *$ & $.35 * *$ & -0.10 & $-.38 * *$ & -0.18 & -0.16 & -0.01 \\
\hline $\begin{array}{l}\text { 3. Time } 1 \text { perceived } \\
\text { hehavinural nntrol }\end{array}$ & $.38 * *$ & $.28 *$ & - & $.43 * *$ & $.26^{*}$ & $.26^{*}$ & $.26^{*}$ & $.64 * *$ & $.32 * *$ & 0.07 & 0.07 & -0.14 & $-.66 * *$ & -0.23 & $-.24 *$ \\
\hline 4. Time 1 intention & 0.19 & $.49 * *$ & $.48 * *$ & - & $.40 * *$ & 0.24 & $.52 * *$ & $.47 * *$ & $.63 * *$ & $.28 *$ & -0.14 & -0.06 & -0.12 & $-.57 * *$ & -0.12 \\
\hline $\begin{array}{l}\text { 5. Time } 1 \text { fruit and } \\
\text { varetahle moncumntion }\end{array}$ & -0.11 & $.35 * *$ & 0.10 & $.35 * *$ & - & 0.22 & 0.18 & $.36^{* *}$ & $.28^{*}$ & $.49 * *$ & -0.05 & -0.18 & -0.04 & -0.19 & $-.54 * *$ \\
\hline 6. Time 2 attitude & $.69 * *$ & $.27 *$ & $.48 * *$ & 0.22 & 0.00 & - & $.37 * *$ & $.45^{* *}$ & $.303 *$ & 0.01 & $.38^{* *}$ & 0.17 & 0.12 & 0.02 & -0.22 \\
\hline $\begin{array}{l}\text { 7. Time } 2 \text { subjective } \\
\text { norm }\end{array}$ & 0.22 & $.55^{* *}$ & $.39 * *$ & $.48 * *$ & 0.12 & $.36^{* *}$ & - & $.42 * *$ & $.55^{* *}$ & 0.24 & 0.05 & $.47 * *$ & 0.08 & -0.06 & 0.04 \\
\hline $\begin{array}{l}\text { 8. Time } 2 \text { perceived } \\
\text { hehavinural nntrol }\end{array}$ & $.39 * *$ & $.37 * *$ & $.74 * *$ & $.43 * *$ & 0.19 & $.57 * *$ & $.52 * *$ & - & $.43 * *$ & 0.07 & 0.17 & 0.12 & 0.16 & -0.13 & $-.31^{*}$ \\
\hline 9. Time 2 intention & 0.24 & $.35 * *$ & $.43 * *$ & $.57 * *$ & $.37 * *$ & $.43 * *$ & $.48 * *$ & $.49 * *$ & - & 0.09 & -0.14 & 0.04 & 0.02 & $.28^{*}$ & -0.20 \\
\hline $\begin{array}{l}\text { 10. Time } 2 \text { fruit and } \\
\text { veretahle mncumntion }\end{array}$ & -0.13 & $.30 *$ & 0.02 & $.27 *$ & $.67 * *$ & 0.06 & 0.18 & 0.17 & $.35 * *$ & - & -0.22 & -0.12 & -0.03 & $-.26^{*}$ & $.47 * *$ \\
\hline 11. Change in attitude & $-.52 * *$ & -0.11 & 0.02 & -0.01 & 0.12 & $.25^{*}$ & 0.13 & 0.16 & 0.19 & 0.24 & - & 0.17 & 0.08 & 0.03 & -0.17 \\
\hline $\begin{array}{l}\text { 12. Change in } \\
\text { subjective norm } \\
\text { 13. Change in }\end{array}$ & -0.16 & $-.65 * *$ & -0.07 & -0.20 & $-.26^{*}$ & 0.02 & $.28 *$ & 0.05 & 0.04 & -0.18 & 0.24 & - & $.30 *$ & 0.11 & 0.06 \\
\hline $\begin{array}{l}\text { perceived behavioural } \\
\text { control }\end{array}$ & -0.12 & -0.08 & $-.53 * *$ & -0.10 & -0.01 & 0.02 & 0.09 & 0.17 & 0.00 & 0.19 & 0.18 & 0.17 & - & 0.17 & 0.01 \\
\hline 14. Change in intention & -0.01 & $-.32 * *$ & -0.13 & $-.64 * *$ & -0.15 & 0.15 & -0.11 & -0.05 & $.25^{*}$ & 0.02 & 0.19 & $.27 *$ & 0.12 & - & -0.05 \\
\hline
\end{tabular}


15. Change in fruit and

$-0.07$

0.01

$-0.17$

$-0.16$

$-.30 *$

0.07

0.09

0.00

0.02

$.51 * *$

0.17

0.08

$.25^{*}$

0.21

** Correlation is significant at the 0.01 level, * Correlation is significant at the 0.05 level. Control group correlations: above the diagonal. Intervention group correlations: below the diagonal. 


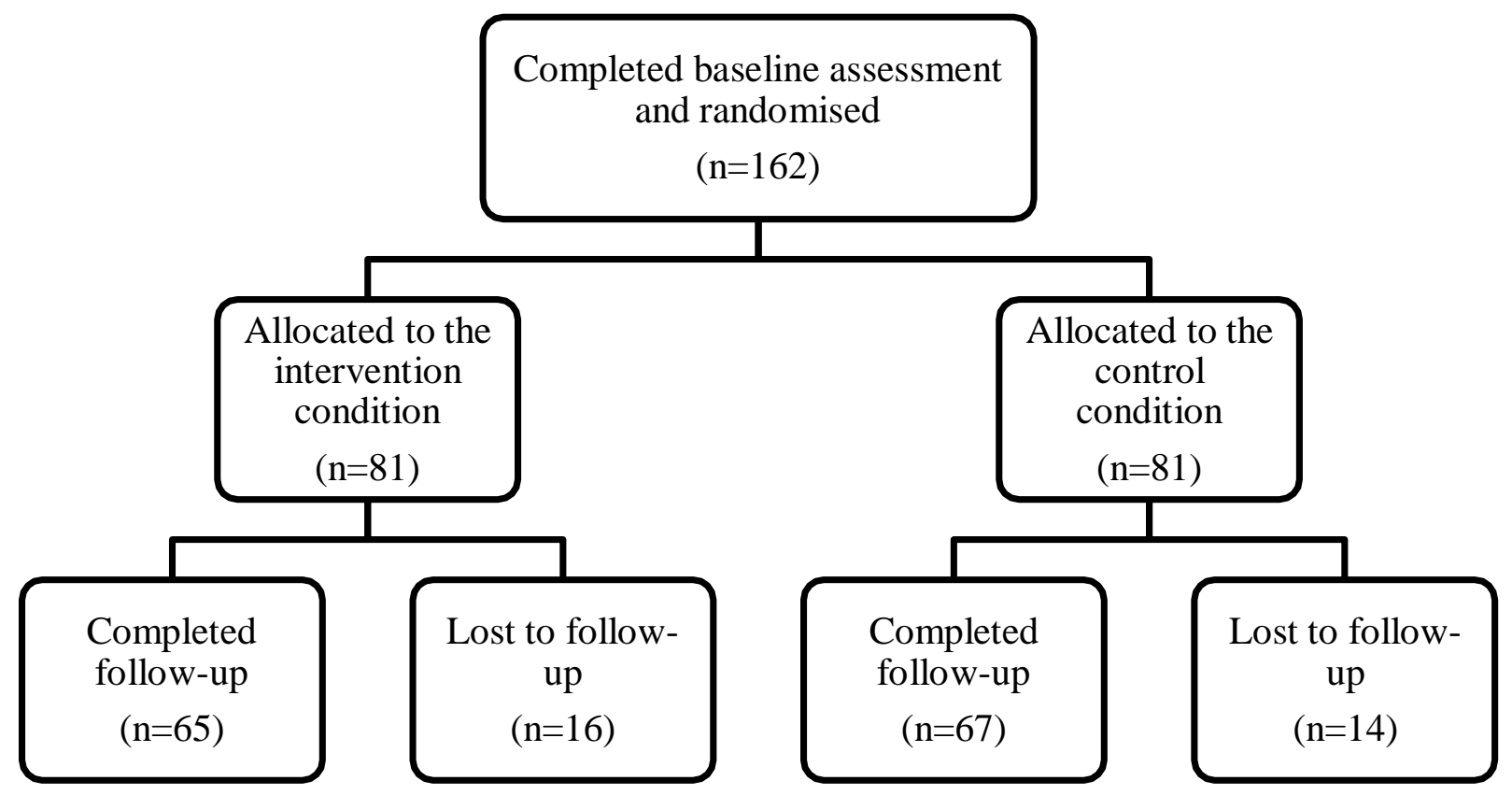

Figure 1. CONSORT Diagram: Flow of the participants through the study. 


\section{Appendix A}

\section{Sample Fresh Facts intervention message text}

\section{Hi [Participant Name]}

\section{Did you know?}

Many people don't know about the links between fruit and vegetable intake and disease.

Did you know that $9 \%$ of cancer in Australia is caused by not eating enough fruit and veg?

Eating at least two servings of fruit and five servings of vegetables each day reduces your risk of cancer as well as slashing your risk of cancer, stroke, heart disease, and obesity.

\section{Increasing your fruit and vegetable consumption one step at a time}

For most people, increasing fruit and vegetable consumption is about making small changes to their life. You can increase your fruit and vegetable consumption - and improve your health - by making lots of little changes.

A $200 \mathrm{ml}$ glass of juice is serving of fruit. Adding a glass of juice to your day is an easy and quick way to up your fruit intake. Why not add a glass of juice to your breakfast every day this week?

Remember, each serving of fruit and vegetables you add to your day is doing you good.

\section{Hannah's TopPick}

Fresh Facts is all about helping young people improve their eating habits. To keep you on track we include advice and success stories from other people who've done Fresh Facts before. Today's TopPick is from Hannah, 19.

"After Fresh Facts, I eat at least 2 fruit and 5 veg every day - and I think everyone should as well. I really believe you are what you eat. When you eat junk food you will feel moody, tired and lazy. But if you eat fruit and vegetables you get doses of vitamins that make you feel good". 


\section{Hi [Participant Name]}

\section{How do you measure up?}

When trying to increase your fruit and vegetable intake it can be helpful to think about the eating habits of other people in your life.

Think about how your friends and family include fruit and vegetables in their lives. How do you measure up?

If there are people in your life who are especially good at eating well, why not ask them how they do it? Talking to others can give you ideas about how to improve your own habits.

\section{Sam's TopPick}

Fresh Facts is all about helping young people improve their eating habits. To keep you on track we include advice and success stories from other people who've done Fresh Facts before. Today's TopPick is from Sam, 18.

"Eating a variety of fruit and veg is important to maintain optimal health and keeps me from getting sick. Eating well helps me have a healthy immune system by making sure I get all the vitamins and minerals I need. It keeps me healthy and makes sure I always look and feel my best".

\section{Did you know?}

Fresh fruit and vegetables taste great - but they are not the only option. One easy way to increase the amount of fruit and vegetables you eat without having to go to the shops all the time is to eat tinned, frozen, or dried fruits and vegetables.

Did you know that frozen peas are better for you than fresh peas you buy at the supermarket? Lots of fruit and veg are as good for you - if not better - when you buy them frozen. This is because when foods are snap frozen all the nutrients are locked in. This makes it even easier to eat well. 


\title{
Hi [Participant Name]
}

\author{
Lisa's TopPick
}

Fresh Facts is all about helping young people improve their eating habits. To keep you on track we include advice and success stories from other people who've done Fresh Facts before. Today's TopPick is from Lisa, 19.

"Fruit and vegetables are good for your general health. They provide you with much needed vitamins and minerals. For me the best way to eat well is to plan ahead. I order my food online and always order a variety of fresh, frozen and tinned produce. That way I never end up having to eat five carrots and two apples every day just so I can eat my two and five. Having variety makes it easy".

\section{Did you know?}

Most people don't talk about fruit and vegetables with their friends - so they often underestimate the number of people who do consume the recommended quantities of fruit and vegetables. We surveyed healthy young adults - people just like you - as part of Fresh Fact's development. More than $65 \%$ of healthy young adults eat fruit and vegetables every day. If they can do it, you can too!

\section{Why not try a simple recipe today?}

This recipe makes one serving of pasta sauce and includes 5 servings of vegetables. That is enough for the whole day!

Fresh Facts Tomato, Mushroom and Baby Spinach Pasta Sauce

Take 1 cup of tomato pasta sauce (about half a jar), 1 large handful of baby spinach, one medium carrot (grated) and about 6 button mushrooms (sliced).

While you're cooking a serve of your favourite pasta, place the tomato based past sauce, mushrooms and carrot in a saucepan. Simmer over medium heat until the mushroom and carrot are softened. Take off the heat and stir through the baby spinach. Toss through your favourite pasta, add salt and pepper to taste and ENJOY!

This recipe is quick to prepare and taste great. For more simple recipes why not ask some friends and family, or look around online. 